\title{
HSATII RNA
}

National Cancer Institute

\section{Source}

National Cancer Institute. HSATII RNA. NCI Thesaurus. Code C148070.

A 30 base to 800 base ribonucleic acid derived from transcription of demethlyated human satellite II (HSAT II) DNA sequences. This ribonucleotide may sequester chromatin regulatory proteins and may be a biomarker for various cancers. 